\title{
Anti-atherogenic effect of soya and rice-protein isolate, compared with casein, in apolipoprotein E-deficient mice
}

\author{
Weihua Ni, Yasuyuki Tsuda, Shinichiro Takashima, Hiroyoshi Sato, Masao Sato and \\ Katsumi Imaizumi ${ }^{\star}$ \\ Laboratory of Nutrition Chemistry, Division of Bioresource and Bioenvironmental Sciences, Graduate School, \\ Kyushu University, Fukuoka 812-8581, Japan
}

(Received 18 June 2002 - Revised 20 January 2003 - Accepted 31 January 2003)

\begin{abstract}
Our objective was to determine whether dietary plant proteins such as soya-protein isolate (SPI) and rice-protein isolate (RPI) compared with animal proteins, such as casein, could afford beneficial effects on atherosclerosis development in apolipoprotein E-deficient mice. In experiment 1, male and female mice were fed on a purified diet containing either casein, SPI or RPI for 9 weeks. The en face lesion area in the aorta $(P<0.05)$ and the lesion size in the aortic root $(P<0.05)$ in mice fed the casein-based diet were greater than those in the SPI or RPI groups. The plant protein groups had an increased concentration of serum L-arginine $(P<0 \cdot 05)$ and $\mathrm{NO}$ metabolites $\left(\mathrm{NO}_{2}\right.$ plus $\left.\mathrm{NO}_{3}\right)$ $(P<0.05)$ than did the casein group. The inhibitory effect of the plant proteins on the lesion formations was unrelated to gender and total serum cholesterol. In experiment 2 , the L-arginine and L-methionine contents were the same in the L-arginine-supplemented casein-based and SPI-based diets, and between the L-methionine-supplemented SPI-based and the casein-based diets. Male mice were fed on the diets for 15 weeks. There were no significant differences in the en face lesion area and the lesion size between the casein group and the L-argi-

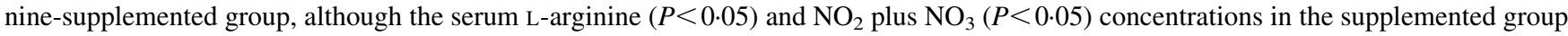
were higher than those in the casein group. There were no significant effects of L-methionine supplementation on the lesion formations. In experiment 3, male mice were given the casein-based diet or the L-arginine-supplemented casein-based diet together with water or water containing an NO synthesis inhibitor for 9 weeks. When given the casein-based diet, the inhibitor drinking, compared with water drinking, resulted in a reduction of the serum $\mathrm{NO}_{2}$ plus $\mathrm{NO}_{3}$ concentration $(P<0.01)$ and an increase in the en face lesion area $(P<0.05)$ and the lesion size $(P<0 \cdot 01)$. When given the L-arginine-supplemented diet, the inhibitor drinking, compared with water drinking, resulted in no increase in the lesion area and size. These results demonstrate anti-atherogenic potentials of SPI- as well as RPI-derived proteins, but their L-arginine and L-methionine contents were not sufficient enough to explain the underlying mechanism(s).
\end{abstract}

Apolipoprotein-E-deficient mice: L-Arginine: Atherosclerosis: Soya protein: Rice protein

Soya and rice proteins are known to be rich in L-arginine and poor in L-methionine compared with animal proteins such as casein. It has recently been reported that these amino acids are differently involved in atherosclerosis in experimental animals such as rabbits, pigs, and LDL receptor-deficient mice (Cooke \& Tsao, 1997). In fact, dietary supplementation of L-arginine prevents atherosclerosis development, probably through the conversion to NO, which has a variety of beneficial effects on the cardiovascular system (Cooke et al. 1992; Böger et al. 1996; Aji et al. 1997). However, there is a report showing that L-arginine treatment does not improve lesion formations in apolipoprotein (apo) E-deficient mice, an animal model of human atherosclerosis (Nakashima et al. 1994), fed a Westerntype diet (Kuhlencordt et al. 2001). In contrast, supplementation of L-methionine to a non-purified diet has been reported to induce typical arteriosclerotic lesions in rabbits (Toborek et al. 1995; Hofmann et al. 2001), possibly through conversion of L-methionine to homocysteine (Zhou et al. 2001). We reported that the en face lesion area in the aorta and the lesion size in the aortic root in apo E-deficient mice fed a diet containing soya protein were smaller than those in the casein-fed groups (Ni et al. 1998). Therefore, if these two amino acids were involved in the development of atherosclerosis, it would be expected that a rice protein-containing diet would result in a decrease in lesion formations in experimental animals including apo E-deficient mice compared with those fed a casein-containing diet.

In the present study, the aim was to show that apo E-deficient mice fed a diet containing soya or rice protein had a lowered extent of atherosclerotic lesion formations in the aorta and in the aortic root than did those fed a casein-containing diet. Then, an L-arginine-supplemented casein-based diet or an L-methionine-supplemented soya protein-based diet was fed to apo E-deficient mice, 
to examine if the beneficial effect of the plant proteins could be attributed to these amino acids. Finally, a role of NO synthesis in the development of atherosclerosis was examined by treating apo E-deficient mice with an inhibitor of NO synthesis.

\section{Materials and methods}

\section{Animals and diets}

C57BL/6J apo E-deficient mice engineered at the University of North Carolina (Chapel Hill, NC, USA) (Zhang et al. 1992) were purchased from the Jackson Laboratory (Bar Harbor, ME, USA) in 1994, and maintained at the Laboratory of Animal Experiments in Kyushu University Faculty of Medicine (Fukuoka, Japan). They were housed in plastic cages (one mouse per cage, $120 \mathrm{~mm} \times 170 \mathrm{~mm} \times 240 \mathrm{~mm}$ ) containing paper chips (ALPHA-dri; Shepherd Specialty Papers, Inc., Kalamazoo, MI, USA), kept in a temperature-controlled room at $23-25^{\circ} \mathrm{C}$ with a $12 \mathrm{~h}$ light-dark cycle (light on 08.00-20.00 hours) and given free access to diet and non-ionized water throughout the experimental period. The diet and water were changed every other day and body weight and food intake were recorded simultaneously.

The composition of a basal diet, based on the AIN-93G formulation (Reeves et al. 1993), has been described previously (Ni et al. 1998; Ando et al. 2002), except that, as a source of dietary fat, olive oil $(100 \mathrm{~g} / \mathrm{kg}$ diet $)$ was used, instead of soyabean oil. The basal diet contained $(\mathrm{g} / \mathrm{kg})$ : casein 200.0; olive oil 100.0; $\alpha$-maize starch 132.0; sucrose 100.0; cellulose 50.0; vitamin mixture (AIN-93G) 10.0; mineral mixture (AIN-93G) 35.0; L-cysteine 3.0; choline bitartrate 2.5 ; tert-butylhydroquinone 0.014 ; maize starch to $1000 \mathrm{~g}$. Diets were packed in a pouch containing an $\mathrm{O}_{2}$ absorbent, flushed with $\mathrm{N}_{2}$ and stored at $4^{\circ} \mathrm{C}$. The diets were freshly prepared every week, and changed every $2 \mathrm{~d}$, with any remaining diet being discarded.

In the first experiment, fifteen female and fifteen male apo E-deficient mice, 12-13 weeks old, were divided into three groups each and fed for 9 weeks the basal diet containing (per $\mathrm{kg}$ diet) $200.0 \mathrm{~g}$ casein $(142 \mathrm{mg} \mathrm{N} / \mathrm{g}$ protein; Wako Pure Chemicals, Osaka, Japan), 211.0 g soya-protein isolate (SPI, $133 \mathrm{mg} \mathrm{N} / \mathrm{g}$ protein, Fujipro R; Fuji Oil, Osaka, Japan) or $213.0 \mathrm{~g}$ rice-protein isolate (RPI, $132 \mathrm{mg}$ $\mathrm{N} / \mathrm{g}$ protein), as a source of dietary protein. The RPI was prepared according to the method described by Morita \& Kiriyama (1993). In brief, $5 \mathrm{~kg}$ rice grits of Oryza sativa L. Japonica (cv. Todoroki) (Shimada Chemical Co., Niigata, Japan) was digested with 10 litres of distilled water containing $60 \mathrm{ml}$ of a heat stable $\alpha$-amylase (Termamyl $120 \mathrm{~L}$; Novo Laboratories, Sapporo, Japan) at $97^{\circ} \mathrm{C}$ for $2 \mathrm{~h}$, and the residue was washed with boiling water followed by ethanol. The N content (Miller \& Houghton, 1945) and amino acid composition (Chang et al. 1986) of the three proteins were determined. The proportion of L-arginine and L-methionine (mol \%) was 3.5 and 2.8 for casein, 7.4 and 1.4 for SPI and 8.1 and 2.2 for RPI, respectively. The amino acid compositions of casein, SPI and RPI were similar to those reported elsewhere (Morita et al. 1997).
In the second experiment, twenty male apo E-deficient mice, 9-10 weeks old, were divided into four groups and fed the casein-based diet, the casein-based diet with supplementation of L-arginine $(6.9 \mathrm{~g} / \mathrm{kg}$ diet $)$, the SPI-based diet and the SPI-based diet with supplementation of L-methionine $(2.4 \mathrm{~g} / \mathrm{kg}$ diet $)$ for 15 weeks. Thus, the L-arginine and L-methionine contents were the same in the L-arginine-supplemented casein-based and SPI-based diets, and between the L-methionine-supplemented SPIbased and the casein-based diets.

In the third experiment, twenty-nine male apo E-deficient mice, 11-12 weeks old, were divided into four groups and fed the casein-based diet or the caseinbased diet with supplementation of L-arginine, as described in the second experiment, and given either with nonionized water or non-ionized water containing $400 \mathrm{mg}$ $\mathrm{N}^{\omega}$-nitro-L-argininemethylester (L-NAME)/l (Sigma, Tokyo, Japan), an NO synthase inhibitor (Aji et al. 1997), for 9 weeks.

These experiments were carried out under the guidelines for Animal Experiments in the Faculty of Agriculture and the Graduate Course, Kyushu University, Fukuoka, Japan and the Law (no. 105) and Notification (no. 6) of the Government of Japan. Animals were killed by withdrawing blood from the left ventricle under anaesthesia with intraperitoneal injection of Somnopentyl $(50 \mathrm{mg} / \mathrm{kg}$ body weight, pentobarbital sodium; Kyoritsu Shoji, Tokyo, Japan).

\section{Tissue preparation and morphometric determination of atherosclerosis}

Animals were killed by withdrawing blood, and the circulatory system was perfused with $50 \mathrm{ml} \mathrm{PBS}, \mathrm{pH} 7 \cdot 4$, via a cannula inserted into the left ventricle, allowing unrestricted efflux from an incision in the vena cava. Perfusion was continued with $50 \mathrm{ml} 10 \%(\mathrm{v} / \mathrm{v})$ neutral formalin buffer solution, $\mathrm{pH} 7.4$. The heart and the aorta were removed and fixed in $10 \%$ neutral formalin-buffered solution. The percentage of the aortic surface covered by lesions was determined using an en face preparation as described previously ( $\mathrm{Ni}$ et al. 1998). To determine the cross-sectional lesion area, hearts containing aortic roots were processed for the quantitative atherosclerosis assay using a modification of the method described by Paigen et al. (1987). Briefly, the heart was cut along a plane between the tip of two atria and the top half was embedded in paraffin. Serial sections $(10 \mu \mathrm{m}$ thick) were prepared from the ascending aorta to the aortic sinus until the aortic tissue was invisible. The sections were mounted on glass slides and stained with elastic Van Gieson and haematoxylin as described previously ( $\mathrm{Ni}$ et al. 1998). Five sections of each heart were selected for intimal area determination. The first and most distal sections to the heart were taken where the aortic valve was just visible, from this section, moving to the base of the heart, the 15 th, 30th, 45th and 60th sections were also photographed along with the first one, using a video camera mounted on an Olympus IX70 light microscope (Olympus Optical, Tokyo, Japan). The intimal area was measured by NIH image/68k 1.57 software (National Institute of Health, 
Bethesda, MD, USA) on a Macintosh computer. The mean intimal area was calculated for each animal and subsequently for each group.

\section{Analysis of serum free amino acid, lipid and nitrite plus nitrate}

Serum free amino acid concentrations were determined as described previously (Ikeda et al. 1994). Serum lipid concentrations were determined by commercially available kits (Cholesterol C Test, Triglyceride G Test and Phospholipid B Test; Wako Pure Chemicals, Osaka, Japan). In order to determine the serum nitrite plus nitrate $\left(\mathrm{NO}_{2}\right.$ plus $\mathrm{NO}_{3}$ ) (final metabolites of $\mathrm{NO}$ ) concentration, $100 \mu \mathrm{l}$ serum was mixed with $40 \mu \mathrm{l} 35 \%$ (w/v) sulfosalicylic acid and centrifuged at $3000 \mathrm{rpm}$ at room temperature for $15 \mathrm{~min}$ to precipitate the lipoproteins and haemoglobin as described previously (Wishnok et al. 1996). The $\mathrm{NO}_{2}$ plus $\mathrm{NO}_{3}$ concentrations in the supernatant fraction were measured by an $\mathrm{NO}_{2} / \mathrm{NO}_{3}$ Assay Kit-C (Wako Pure Chemicals, Osaka, Japan) according to the manufacturer's instructions.

\section{Statistical analysis}

Data are expressed as means with their standard errors and were analysed by two- or one-way ANOVA followed by a post-hoc test (Fisher's protected least significant difference test) in the first and the second experiment, and by Student's $t$ test in the third experiment. In all cases, the effects were considered statistically significant at $P<0 \cdot 05$.

\section{Results}

\section{Effect of dietary protein}

There was a difference in the initial mean body weight between females; (25.5 (SE 1.2), 24.8 (SE 0.7) and 24.8 (SE 0.8) $\mathrm{g}$ for the casein, SPI and RPI groups, respectively) and males (29.5 (SE 1.9), 29.4 (SE 1.7) and 30.8 (SE 1.7) $\mathrm{g}$ for the casein, SPI and RPI groups, respectively); $P<0.01$. Final mean body weight in females, (29.4 (SE 2.6), 27.5 (SE 1.0) and 28.3 (SE 1.8) $\mathrm{g}$ for the casein, SPI and RPI groups, respectively) was smaller than that in males, (39.5 (SE 3.5), 37.0 (SE 1.8) and 38.0 (SE 2.9) $\mathrm{g}$ for the casein, SPI and RPI groups, respectively); $P<0 \cdot 01$, but there was no significant dietary effect. Gender and type of dietary protein had no significant effect on the mean daily food intake: 4.17 (SE 0.15), 4.59 (SE 0.17) and 4.45 (SE 0.19) $\mathrm{g}$ for the casein-, SPI- and RPI-fed females, respectively; and 4.38 (SE 0.14), 4.73 (SE 0.16) and 4.40 (SE 0.10) $\mathrm{g}$ for the casein-, SPI- and RPI-fed males, respectively.

Table 1 shows the degree of atherosclerotic lesions, and concentrations of serum L-arginine and L-methionine, $\mathrm{NO}_{2}$ plus $\mathrm{NO}_{3}$ and lipids in the apo E-deficient female and male mice fed a diet containing different proteins. Two-way ANOVA revealed a main effect of protein on the en face lesion area in the aorta $(P<0.01)$, the lesion size in the aortic root $(P<0.05)$ and the serum $\mathrm{NO}_{2}$ plus $\mathrm{NO}_{3}$ concentration $(P<0.05)$; there was no main effect of gender.

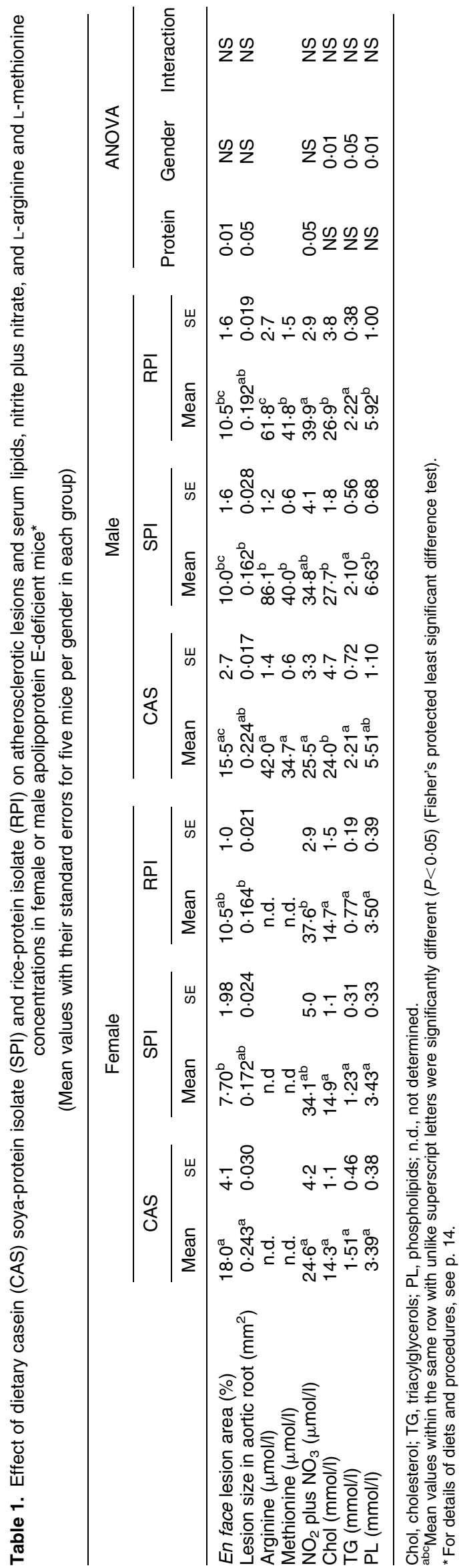


Accordingly, the data were summarized in Fig. 1, stratified by diet but not gender. In contrast, there was a significant main effect of gender on the concentrations of serum cholesterol $(P<0.01)$, triacylglycerols $(P<0.05)$ and phospholipids $(P<0.01)$; the concentrations of these lipids were lower in females than in males. Dietary protein had no significant effect on the serum lipids. Reflecting the dietary content of L-arginine, the serum L-arginine concentration in male apo E-deficient mice was higher when plant proteins were given than when casein was consumed $(P<0 \cdot 05)$. The concentration of L-methionine in the casein group was lower than that in the plant protein groups $(P<0.05)$, although the dietary proportion of L-methionine in casein was approximately 2 -fold as high as in SPI.

As shown in Fig. 1, the en face lesion area in the casein group was significantly greater than in the SPI $(P<0.01)$ and the RPI $(P<0.01)$ groups. The lesion size in the casein group was also significantly greater than in the SPI $(P<0.01)$ and the RPI $(P<0.05)$ groups. The serum $\mathrm{NO}_{2}$ plus $\mathrm{NO}_{3}$ concentration in the casein group was significantly lower than in the SPI $(P<0.05)$ and the RPI $(P<0 \cdot 01)$ groups.

\section{Effect of supplementation of amino acids}

There were no differences in the initial mean body weight among the groups (26.5 (SE 0.3), 25.3 (SE 0.6), 25.6 (SE 0.7) and 26.1 (SE 0.8) g for the casein, casein plus L-arginine, SPI, and SPI plus L-methionine groups, respectively) and the final mean body weight (34.2 (SE 1.9), 34.1 (SE 1.8), 32.0 (SE 1.7) and 35.6 (SE 1.1) g for the casein, casein plus L-arginine, SPI, and SPI plus L-methionine groups, respectively). Mean daily food intake in both groups of mice fed the casein-based diet (3.80 (SE 0.15) and 3.61 (SE 0.06) $\mathrm{g}$ for the casein and casein plus L-arginine groups, respectively) was lower than that in both groups of mice fed the SPI-based diet (4.24 (SE 0.04) and 4.34 (SE 0.05) $\mathrm{g}$ for the SPI and SPI plus L-methionine group, respectively); $P<0 \cdot 01$.

Table 2 shows the degree of atherosclerotic lesions, and concentrations of the serum L-arginine, L-methionine, $\mathrm{NO}_{2}$ plus $\mathrm{NO}_{3}$ and lipids in male apo E-deficient male mice fed a diet with or without supplementation of amino acids. There was no significant difference in the en face lesion area in the aorta among the four dietary groups. These results are in contrast to those in experiment 1 where there was a significant difference in the lesion area between the casein and the SPI groups. It is probable that the feeding period influenced the results. The lesion size in the aortic root in mice fed the SPI diet and SPI plus L-methionine diet was lower than that in the casein group $(P<0 \cdot 05)$. There was no difference in the lesion size between the casein and the casein plus L-arginine groups $(P=0.08)$, and between the SPI and the SPI plus L-methionine
(A)

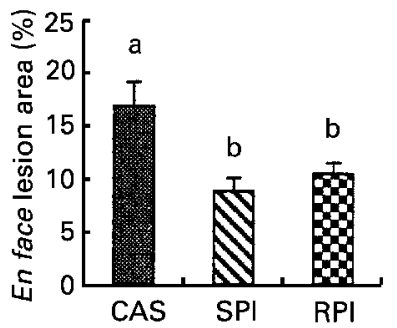

(B)

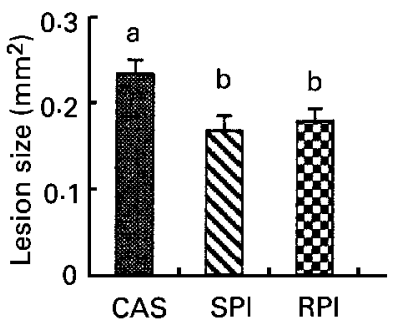

(C)

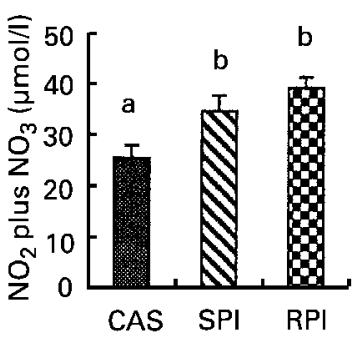

Fig. 1. En face lesion area in the aorta (A), lesion size in the aortic root (B) and NO metabolites in the serum of mice fed a diet containing casein (CAS), soya-protein isolate (SPI) and rice-protein isolate (RPI). Mean values for ten mice per group are shown, with their standard errors represented by vertical bars. abc Mean values with unlike letters were significantly different $(P<0.05)$.

Table 2. Effect of supplementation of L-arginine and L-methionine to casein (CAS)- and soya-protein isolate (SPI)-based diets, respectively, on atherosclerotic lesions and serum lipids, nitrite plus nitrate, and L-arginine and L-methionine concentrations in male apolipoprotein E-deficient mice*

(Mean values with their standard errors for five male mice in each group)

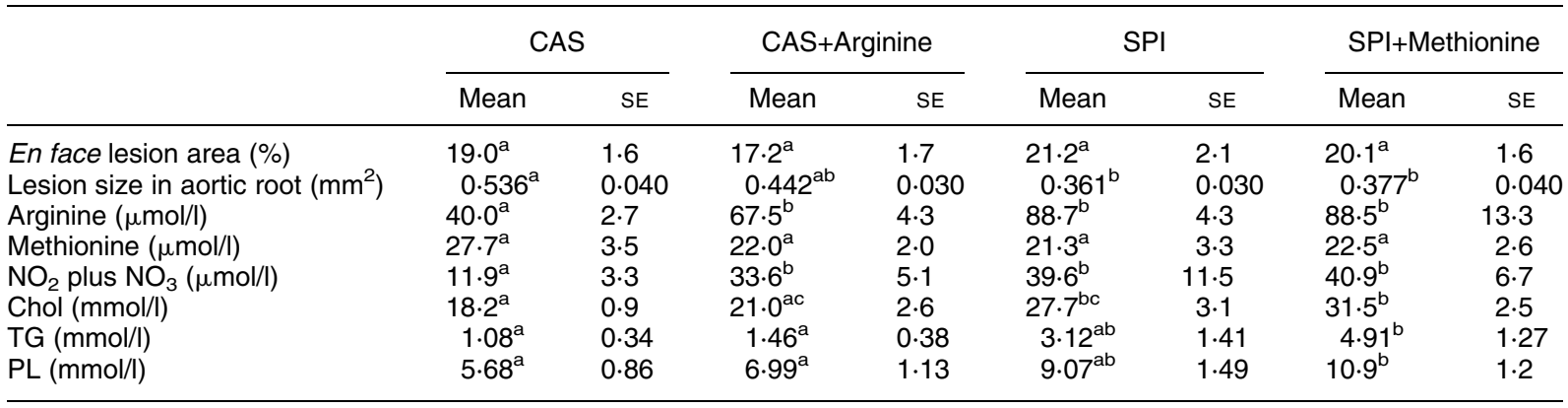

Chol, cholesterol; TG, triacylglycerols; PL, phospholipids.

${ }^{\mathrm{abc}}$ Mean values within the same row with unlike superscript letters were significantly different $(P<0.05)($ Fisher's protected least significant difference test).

${ }^{*}$ For details of diets and procedures, see p. 14 
groups, respectively. There was no difference in the lesion area between the SPI and the SPI plus L-methionine groups. The serum L-arginine concentration in the SPI, SPI plus L-methionine and casein plus L-arginine groups was higher than that in the casein group $(P<0 \cdot 05)$. The serum L-methionine concentration was not affected by the dietary protein or amino acid supplementation. The serum $\mathrm{NO}_{2}$ plus $\mathrm{NO}_{3}$ concentration in the SPI, SPI plus L-methionine, and the casein plus L-arginine groups was higher than that in the casein group $(P<0.05)$. Supplementation of L-methionine had no effect on the serum $\mathrm{NO}_{2}$ plus $\mathrm{NO}_{3}$ concentration. The amino acid supplementation had no significant effect on the serum lipids. The SPI-based diet, in comparison with the casein-based diet, tended to increase the serum lipid concentration.

\section{Effect of nitric oxide synthesis inhibitor}

There were no differences in the initial mean body weight among the groups (28.8 (SE 0.5), 28.9 (SE 0.6), 29.4 (SE 0.7) and 29.4 (SE 0.6) $\mathrm{g}$ for the casein, casein plus L-NAME, casein plus L-arginine, and casein plus L-arginine plus L-NAME groups, respectively), and the final mean body weight (38.1 (SE 2.0), 41.8 (SE 1.4), 39.1 (SE 1.4) and 41.4 (SE 1.6) $\mathrm{g}$ for the casein, casein plus L-NAME, casein plus L-arginine, and casein plus L-arginine plus L-NAME groups, respectively). There were no differences in mean daily food intake among the groups (4.54 (SE 0.18), 4.48 (SE 0.11), 4.74 (SE 0.08) and 4.41(SE 0.12) $\mathrm{g}$ for the casein, casein plus L-NAME, casein plus L-arginine, and casein plus L-arginine plus L-NAME groups, respectively). Mean daily water intake was also similar among the groups (3.30 (SE 0.18), 3.18 (SE 0.15), 3.46 (SE 0.23) and 3.67 (SE 0.33) $\mathrm{ml}$ for the casein, casein plus L-NAME, casein plus L-arginine, and casein plus L-arginine plus L-NAME groups, respectively).

Table 3 shows the degree of atherosclerotic lesions, and concentrations of the serum L-arginine, L-methionine, $\mathrm{NO}_{2}$ plus $\mathrm{NO}_{3}$ and lipids in male apo E-deficient mice fed casein or casein plus L-arginine and given water with or without supplementation of L-NAME. Two-way ANOVA revealed a main effect of L-NAME on the en face lesion area in the aorta $(P<0 \cdot 01)$. The lesion area in the casein plus L-NAME group was significantly greater than in the casein group $(P<0 \cdot 05)$, but there was no significant difference in the lesion area between the casein plus $\mathrm{L}$-arginine and the casein plus L-arginine plus L-NAME groups $(P=0 \cdot 08)$. There was an interactive effect of L-arginine supplementation and L-NAME treatment on the lesion size in the aortic root $(P<0 \cdot 05)$. The lesion size in the casein plus L-NAME group was the highest among groups $(P<0 \cdot 01)$, but there was no significant difference in the lesion size between the casein plus L-arginine and the casein plus L-arginine plus L-NAME groups. As expected, there was a supplementary L-arginine effect on the serum L-arginine concentration $(P<0 \cdot 01)$. Two-way ANOVA revealed a main effect of L-NAME on the serum $\mathrm{NO}_{2}$ plus $\mathrm{NO}_{3}$ concentration $(P<0 \cdot 01)$. Although there was an L-arginine effect on $\mathrm{NO}_{2}$ plus $\mathrm{NO}_{3}$ $(P<0.05)$, the mean values between the casein and the casein plus L-arginine $(P=0.071)$ and those between casein plus $\mathrm{L}$-arginine and casein plus L-arginine plus L-NAME $(P=0 \cdot 16)$ were not significant. There were main effects of L-NAME treatment $(P<0.01)$ and L-arginine supplementation $(P<0.05)$ on the serum cholesterol concentration. The serum cholesterol concentration in the casein plus L-arginine plus L-NAME group was higher than that in the casein group $(P<0.05)$, but there were no significant differences between the casein plus L-arginine plus L-NAME and the casein plus L-NAME groups $(P=0.089)$ and between the casein plus L-NAME plus L-arginine and the casein plus L-arginine groups $(P<0.058)$.

\section{Discussion}

The first experiment showed that both RPI and SPI, in comparison with casein, were effective to the same extent to lower atherosclerotic lesion formations in the aorta (en face lesion area) and aortic root (lesion size)

Table 3. Effect of nitric oxide synthase inhibitor on atherosclerotic lesions and serum lipids, nitrite plus nitrate, and L-arginine and L-methione (Met) concentrations in male apolipoprotein E-deficient mice*

(Mean values with their standard errors for seven male mice for CAS, CAS+Arg, and CAS+Arg+L-NAME groups, respectively, and eight male mice for CAS+L-NAME group)

\begin{tabular}{|c|c|c|c|c|c|c|c|c|c|c|c|}
\hline & \multicolumn{2}{|c|}{ CAS } & \multicolumn{2}{|c|}{ CAS+L-NAME } & \multicolumn{2}{|c|}{ CAS+Arg } & \multicolumn{2}{|c|}{$\begin{array}{l}\text { CAS+Arg+L- } \\
\text { NAME }\end{array}$} & \multicolumn{3}{|c|}{ ANOVA } \\
\hline & Mean & SE & Mean & SE & Mean & SE & Mean & SE & Arg & L-NAME & Int \\
\hline En face lesion area (\%) & $8 \cdot 04^{a}$ & $1 \cdot 00$ & $14 \cdot 0^{b}$ & $2 \cdot 0$ & $9 \cdot 05^{\mathrm{ac}}$ & 1.60 & $13 \cdot 6^{\mathrm{bc}}$ & $2 \cdot 1$ & NS & 0.01 & NS \\
\hline Lesion size in aortic root $\left(\mathrm{mm}^{2}\right)$ & $0.188^{a}$ & 0.021 & $0.312^{b}$ & 0.023 & $0 \cdot 15^{\mathrm{a}}$ & 0.017 & $0.173^{a}$ & 0.013 & 0.01 & 0.01 & 0.05 \\
\hline $\operatorname{Arg}(\mu \mathrm{mol} / \mathrm{l})$ & $39 \cdot 1^{\mathrm{a}}$ & $11 \cdot 1$ & $48 \cdot 6^{a}$ & 3.4 & $70 \cdot 5^{\mathrm{b}}$ & 6.9 & $69 \cdot 5^{\mathrm{b}}$ & $5 \cdot 1$ & 0.01 & NS & NS \\
\hline Met $(\mu \mathrm{mol} / \mathrm{l})$ & $48 \cdot 6^{\mathrm{a}}$ & 0.8 & $48 \cdot 4^{a}$ & 0.6 & $50 \cdot 8^{a}$ & 1.5 & $48 \cdot 5^{\mathrm{a}}$ & $3 \cdot 4$ & NS & NS & NS \\
\hline Chol $(\mathrm{mmol} / \mathrm{l})$ & $16 \cdot 5^{a}$ & 2.4 & $20 \cdot 6^{\mathrm{ab}}$ & $2 \cdot 0$ & $19 \cdot 9^{\mathrm{ab}}$ & 0.7 & $25 \cdot 3^{\mathrm{b}}$ & $2 \cdot 1$ & 0.05 & 0.01 & NS \\
\hline $\mathrm{TG}(\mathrm{mmol} / \mathrm{l})$ & $2 \cdot 17^{\mathrm{a}}$ & 0.50 & $2 \cdot 23^{a}$ & 0.19 & $1 \cdot 77^{a}$ & 0.13 & $2 \cdot 43^{\mathrm{a}}$ & 0.35 & NS & NS & NS \\
\hline $\mathrm{PL}(\mathrm{mmol} / \mathrm{l})$ & $5 \cdot 86^{\mathrm{a}}$ & 0.81 & $6 \cdot 38^{a}$ & 0.50 & $5 \cdot 74^{a}$ & 0.27 & $7 \cdot 08^{a}$ & 0.54 & NS & NS & NS \\
\hline
\end{tabular}

CAS, casein; Arg, arginine; L-NAME, N ${ }^{\omega}$-nitro-L-argininemethylester; Int, interaction; Chol, cholesterol; TG, triacylglycerols; PL, phospholipids.

${ }^{a b c}$ Mean values within the same row with unlike superscript letters were significantly different $(P<0.05)$ (Fisher's protected least significant difference test).

${ }^{*}$ For details of diets and procedures, see p. 14 
in apo E-deficient mice. This is the first report showing an anti-atherogenic effect of RPI in experimental animals. Since the RPI and SPI preparations were relatively rich in protein (830 and $870 \mathrm{~g} / \mathrm{kg}$ for SPI and RPI, respectively), it is probable that the anti-atherogenic effect of the plantprotein preparations can be attributed to the protein rather than other ingredients such as isoflavones in the SPI, although isoflavones have been shown to exert antiatherogenic effects in experimental animals (Kirk et al. 1998; Yamakoshi et al. 2000; Adams et al. 2002). In fact, our RPI preparations obviously contained no isoflavones. Furthermore, an SPI preparation that was exhaustively washed with ethanol in order to remove as much isoflavones as possible still maintained an ability in apo E-deficient mice to lower the atherosclerotic lesion area in the aorta compared with those fed a diet containing casein (Ni et al. 1998).

Plant proteins derived from soya and rice are rich in L-arginine and poor in L-methionine, in comparison with casein. These differences in amino acid composition between plant and animal proteins might be involved in the extent of the lesion formations. In fact, L-arginine supplementation results in lowering the development of atherosclerotic lesions (Cooke et al. 1992; Böger et al. 1996; Aji et al. 1997), whereas L-methionine supplementation aggravates the lesion (Toborek et al. 1995; Zhou et al. 2001). In experiment 1, the male mice fed the SPI and RPI, compared with those fed the casein, had an increased concentration of serum L-arginine. However, the casein group had a lower concentration of serum L-methionine than did the plant-protein groups. Therefore, it was assumed that the difference in the L-arginine content rather than the L-methionine content in the diet affected the lesion formations in the mice fed the plant proteins and casein, respectively. L-Arginine is the precursor of NO, which exerts beneficial effects on the atherosclerotic lesion formations through mediating endothelium-dependent vasodilator responses of the coronary and peripheral blood vessels (Böger et al. 1995, 1996). Since serum determination of NO metabolites has been suggested to be one of the useful indicators for systemic NO production rates from L-arginine in various physiological and pathophysiological conditions (Bode-Böger et al. 1994), we measured the serum $\mathrm{NO}_{2}$ plus $\mathrm{NO}_{3}$ concentration. In experiment 1 , the SPI- and RPI-fed mice had an increased concentration of serum $\mathrm{NO}_{2}$ plus $\mathrm{NO}_{3}$ than did the casein group. Therefore, it was suggested that the plant protein consumption, in comparison with casein, facilitated production of $\mathrm{NO}$ in the vascular system, due to its high L-arginine content, thereby contributing to lowering the lesion formations.

To examine further a role of L-arginine and L-methionine in the lesion formations, in experiment 2, L-arginine was supplemented to the casein-based diet, or L-methionine to the SPI-based diet; in this way, the L-arginine and L-methionine contents were equivalent to those in SPIand casein-based diets, respectively. Supplementary L-methionine to the SPI diet resulted in neither an elevation of the serum L-methionine nor aggravation of the lesion formations. The L-arginine supplemented group, compared with the casein group, had increased concentrations of serum L-arginine and $\mathrm{NO}_{2}$ plus $\mathrm{NO}_{3}$ to an extent that was in the same range as that in the SPI-based diet-fed groups. The results are in agreement with those who found that the production of $\mathrm{NO}$ and its metabolites by vascular rings was increased above control in rabbits fed L-arginine (Minor et al. 1990; Tsao et al. 1994; Candipan et al. 1996). However, in contrast to the SPI-based diet groups, the L-arginine-supplemented casein-based diet group, compared with the casein group, had no significant prevention from the lesion size in the aortic root. Our results are in agreement with those by Kuhlencordt et al. (2001), who reported that L-arginine supplementation resulted in no significant effect on the lesion area in apo E-deficient mice assayed by an en face method. However, our results are in contrast to Aji et al. (1997) and Böger et al. (1995), who reported that L-arginine supplementation reduced the lesion formations in LDL-receptor knockout mice and hypercholesterolaemic rabbits, respectively. Therefore, the results obtained by Kuhlencordt et al. (2001) and by us indicate that the L-arginine supplementation may not be sufficient enough to lower the lesion formations in apo E-deficient mice. Alternatively, these results suggest that, anti-athergenic potentials of SPI and RPI in experiment 1 should be ascribed to not only an increased NO formation due to high L-arginine content in the plant proteins but also an unclarified factor belonging to the plant proteins. In this context, it remains a possibility that amino acids other than L-arginine and L-methionine in the plant proteins might contribute to reducing the lesion formations, because both SPI and RPI, compared with casein, contain in common an increased proportion of glycine $(41,42$ and $16 \mathrm{~g} / \mathrm{kg}$ for SPI, RPI and casein), and cysteine $(12,22$ and $3.0 \mathrm{~g} / \mathrm{kg}$ for SPI, RPI and casein). It also remains to be determined if an L-argininecontaining peptide present in the SPI and RPI preparations, compared with the free form of L-arginine, might exert an effect that is effective in lowering the lesion formations.

Experiment 3 was carried out to confirm a role of NO formation from L-arginine in lowering the atherosclerotic lesion formations of apo E-deficient mice. For this purpose, the mice were fed a diet containing casein or the caseinbased diet supplemented with L-arginine, and given water or water containing an NO synthesis inhibitor, L-NAME (Aji et al. 1997). When the mice were fed the caseinbased diet without supplementation of L-arginine, L-NAME treatment, compared with no L-NAME, resulted in a prominent reduction in the concentration of serum NO metabolites and an increased lesion area in the aorta and lesion size in the aortic root. These results confirm that an efficient utilization of L-arginine for NO synthesis is a prerequisite for preventing an increase of the lesion formations in apo E-deficient mice. It is, however, interesting to note that L-NAME-treated mice that were given the casein-based diet supplemented with L-arginine had lowered lesion size in the aortic root than did L-NAME-treated mice that were given the diet without L-arginine supplementation, although those mice had a decreased concentration of the serum NO metabolites. These results suggest that an increase of dietary L-arginine could exert a beneficial effect on the lesion formations through a mechanism 
such as becoming a precursor of NO (Böger et al. 1995, 1996) as well as an antioxidant (Böger et al. 1998). However, our results are not in agreement with Aji et al. (1997), who showed that treating LDL-receptor knockout mice with a high-cholesterol diet and L-NAME abolished the beneficial effect of L-arginine supplementation on the lesion size in the aortic root. The discrepancy between our results and those of Aji et al. (1997) might be due to the animals and diets.

Dietary soya protein, compared with animal proteins, has long been known to possess a hypocholesterolaemic effect in a large number of clinical and experimental studies (Beynen, 1992; Anderson et al. 1995; Potter, 1996). Furthermore, SPI and RPI, compared with casein, are hypocholesterolaemic in the rat (Morita et al. 1997). In the present study, however, the SPI- or RPI-based diets, compared with the casein-based diet, did not lower the serum total cholesterol concentration in apo E-deficient mice. In addition, supplementation of L-arginine or L-methionine did not alter the intrinsic effect of SPI and casein on the serum cholesterol concentrations. Furthermore, female mice had significantly lower serum cholesterol concentration than did male mice, but there was no significant difference in the lesion formations between gender. Therefore, it was unlikely that the serum cholesterol level was relevant to the different response of arterial lesion formations to dietary protein source.

Both experiments 1 and 2 showed anomalous results. Namely, the SPI group had a lowered lesion size in the aortic root than did the casein group in both experiments, but there was no significant difference in the lesion area in the aorta between the groups in experiment 2 . Furthermore, dietary proteins resulted in no significant effect on the serum cholesterol concentration in experiment 1 , while it was approximately $50 \%$ higher in the SPI group than in the casein group in experiment 2. This might contribute to the differences in atherosclerosis between the two experiments. Again, this might be attributed to the different length of the experiments. It also seems that experiment 3 was confounded by serum cholesterol. The addition of L-NAME increased the serum cholesterol, which may, at least in part, be responsible for the increase in atherosclerosis.

In summary, the present study showed that dietary SPI and RPI, in comparison with dietary casein, led to reduced lesion formations that appeared to be preceded by an increase in the concentration of the serum L-arginine and NO metabolites. Dietary L-arginine supplementation resulted in an increased concentration of the serum NO metabolites, but this was not accompanied with the lowering of lesion formations. Therefore, antiatherogenic potentials of the plant proteins include not only an increase in the formation of NO from L-arginine but also an uncharacterized factor intrinsic to the SPI and RPI.

\section{Acknowledgements}

This research was supported by Grant-in-Aid for Scientific Research (B) (2) (11460060 and 13460059).

\section{References}

Adams MR, Golden DL, Register TC, et al. (2002) The atheroprotective effect of dietary soy isoflavones in apolipoprotein E-/mice requires the presence of estrogen receptor- $\alpha$. Arterioscler Thromb Vasc Biol 22, 1859-1864.

Aji W, Ravalli S, Szabolcs M, et al. (1997) L-Arginine prevents xanthoma development and inhibits atherosclerosis in LDL receptor knockout mice. Circulation 95, 430-437.

Anderson JW, Johnstone BM \& Cook-Newwell ME (1995) Metaanalysis of the effects of soy protein intake on serum lipids. $N$ Engl J Med 333, 276-282.

Ando M, Tomoyori H \& Imaizumi K (2002) Dietary cholesteroloxidation products accumulate in serum and liver in apolipoprotein E-deficient mice, but do not accelerate atherosclerosis. Br J Nutr 88, 339-345.

Beynen AC (1992) Cholesterolemic effects of dietary soybean protein and casein: mechanism of action. In Dietary Proteins: How They Alleviate Diseases and Promote Better Health, pp. 77-83 [GU Liepa editor]. Champaign, IL: AOCS Press.

Bode-Böger SM, Böger RH \& Creutzig A (1994) L-arginine infusion decreases peripheral arterial resistance and inhibits platelet aggregation in healthy subjects. Clin Sci 87, 303-310.

Böger RH, Bode-Böger SM \& Frölich JC (1996) The L-argininenitric oxide pathway. Role in atherosclerosis and therapeutic implications. Atherosclerosis 127, 1-11.

Böger RH, Bode-Böger SM, Mügge A, et al. (1995) Supplementation of hypercholesterolaemic rabbits with L-arginine reduces the vascular release of superoxide anions and restores NO production. Atherosclerosis 117, 273-284.

Böger RH, Bode-Böger SM, Phivthong-ngam L, et al. (1998) Dietary L-arginine and $\alpha$-tocopherol reduce vascular oxidative stress and preserve endothelial function in hypercholesterolemic rabbits via different mechanisms. Atherosclerosis 141, $31-43$.

Candipan RC, Wang B, Buitrago R, Tsao PS \& Cooke JP (1996) Regression or progression: dependency on vascular nitric oxide. Arterioscler Thromb Vasc Biol 16, 44-50.

Chang KC, Lee CC \& Brown G (1986) Production and nutritional evaluation of high-protein rich flour. J Food Sci 51, 464-467.

Cooke JP, Singer AH, Tsao PS, Zera P, Rowan RA \& Billingham ME (1992) Anti-atherogenic effects of L-arginine in the hypercholesterolemic rabbit. J Clin Invest 90, 1168-1172.

Cooke JP \& Tsao PS (1997) Arginine: a new therapy for atherosclerosis? Circulation 95, 311-312.

Hofmann MA, Lalla E, Lu Y, et al. (2001) Hyperhomocysteinemia enhances vascular inflammation and accelerates atherosclerosis in a murine model. J Clin Invest 107, 675-683.

Ikeda A, Wakamatsu K, Umeda T, et al. (1994) Effects of dietary protein and fat on linoleic and $\alpha$-linolenic acid metabolism and prostacyclin production in stroke-prone spontaneous hypertensive rats. J Nutr Biochem 5, 248-255.

Kirk EA, Sutherland PS, Wang SA, Chait A \& LeBoeuf RC (1998) Dietary isoflavones reduce plasma cholesterol and atherosclerosis in C57BL/6 mice but not LDL receptordeficient mice. $J$ Nutr 128, 954-959.

Kuhlencordt PJ, Chen J, Han F, Astern J \& Huang PL (2001) Genetic deficiency of inducible nitric oxide synthase reduces atherosclerosis and lowers plasma lipid peroxides in apolipoprotein E-knockout mice. Circulation 103, 3099-3104.

Miller L \& Houghton JA (1945) The micro-Kjeldahl determination of the nitrogen content of amino acids and proteins. J Biol Chem 159, 373-380.

Minor RLJ, Myers PR, Guerra RJ, Bates JN \& Harrison DG (1990) Diet-induced atherosclerosis increases the release of nitrogen oxides from rabbit aorta. J Clin Invest 86, 2109-2116. 
Morita T \& Kiriyama S (1993) Mass production method for rice protein isolate and nutritional evaluation. J Food Sci 58, 1393-1396.

Morita T, Oh-hashi A, Takei K, Ikai M, Kasaoka S \& Kiriyama S (1997) Cholesterol-lowering effects of soybean, potato and rice proteins depend on their low methionine contents in rats fed a cholesterol-free purified diet. J Nutr 127, 470-477.

Nakashima Y, Plump AS, Raines EW, Breslow JL \& Ross R (1994) Apo E-deficient mice develop lesions of all phases of atherosclerosis throughout the arterial tree. Arteriosclerosis and Thrombosis 14, 133-140.

Ni W-H, Tsuda Y, Sakono M \& Imaizumi K (1998) Dietary soy protein isolate, compared with casein, reduces atherosclerosis in apolipoprotein E-deficient mice. $J$ Nutr 128, 1884-1889.

Paigen B, Morrow A, Holmes PA, Mitchell D \& Williams RA (1987) Quantitative assessment of atherosclerotic lesions in mice. Atherosclerosis 68, 231-240.

Potter SM (1996) Soy protein and serum lipids. Curr Opin Lipidol 7, 260-264.

Reeves PG, Nielsen FH \& Fahey GC Jr (1993) AIN-93 purified diets for laboratory rodents: final report of the American Institute of Nutrition Ad Hoc Writing Committee on the reformulation of the AIN-76A rodent diet. J Nutr 123, 1939-1951.
Toborek M, Kopieczna-Grzebieniak E, Drózdz M \& Wieczorek M (1995) Increased lipid peroxidation as a mechanism of methionine-induced atherosclerosis in rabbits. Atherosclerosis 115, 217-224.

Tsao PS, McEvoy LM, Drexler H, Butcher EC \& Cooke JP (1994) Enhanced endothelial adhesiveness in hypercholesterolemia is attenuated by L-arginine. Circulation 89, 2176-2182.

Wishnok JS, Glogowski JA \& Tannenbaum SR (1996) Quantitation of nitrate, nitrite, and nitrosating agents. Methods Enzymol 268, 130-141.

Yamakoshi J, Piskula MK, Izumi T, et al. (2000) Isoflavone aglycone-rich extract without soy protein attenuates atherosclerosis development in cholesterol-fed rabbits. $J$ Nutr 130, 1887-1893.

Zhang SH, Reddick RL, Piedrahita JA \& Maeda N (1992) Spontaneous hypercholesterolemia and arterial lesions in mice lacking apolipoprotein E. Science 258, 468-471.

Zhou J, Møller J, Danielsen CC, et al. (2001) Dietary supplementation with methionine and homocysteine promotes early atherosclerosis but not plaque rupture in apo E-deficient mice. Arterioscler Thromb Vasc Biol 21, 1470-1476. 